Voix et Images

voixetimages

\title{
Don Quichotte de la démanche de Victor-Lévy Beaulieu
}

\section{André Vanasse}

Volume 1, numéro 1, septembre 1975

Hubert Aquin

URI : https://id.erudit.org/iderudit/013992ar

DOI : https://doi.org/10.7202/013992ar

Aller au sommaire du numéro

\section{Éditeur(s)}

Les Presses de l'Université du Québec

\section{ISSN}

0318-9201 (imprimé)

1705-933X (numérique)

Découvrir la revue

\section{Citer cet article}

Vanasse, A. (1975). Don Quichotte de la démanche de Victor-Lévy Beaulieu. Voix et Images, 1(1), 128-130. https://doi.org/10.7202/013992ar d'utilisation que vous pouvez consulter en ligne.

https://apropos.erudit.org/fr/usagers/politique-dutilisation/ 


\section{Don Quichotte de la démanche de Victor-Lévy Beaulieu}

Et encore la saga des Beauchemin qui nous est racontée dans ce roman intitulé Don Quichotte de la démanche ${ }^{1}$. Victor-Lévy Beaulieu, tel un Balzac frénétique et dément, terré dans son bungalow de Terrebonne, trop souvent ivre et assailli par d'horribles cauchemars, noircit de milliers de mots les pages blanches de ce qui constituera cette fois-ci l'épopée pitoyable de son "si pauvre frère Abel" (son jumeau, son semblable, son double, son masque?).

Les autres membres de la tribu sont aussi présents: Steven le poète (i) écrit des centaines de lettres à Abel mais ce dernier ne les lit même pas); Gabriella la sœur incestueuse accrochée aux ailes blanches de Steven; Jos, le démoniaque, qui cette fois-ci, au lieu de s'encabaner avec Marie et de vivre avec elle son délire, se promène la nuit dans une sinistre ambulance noire et s'amuse à terroriser les enfants vêtu d'un large chapeau et d'une longue cape noire et affublé de dents de vampire! II a perdu toute passion pour Buddha mais s'occupe activement de mettre sur pied la secte mystique des Porteurs d'Eau!

Et par bouffées cycliques on voit apparaître l'image de Pa Beauchemin, toujours triste et consolant les fous qu'il surveille à l'asile en jouant de l'harmonica.: L'image aussi, plus estompée cependant, de Mathilde, la mère morte d'un cancer au ventre, de grand-père Toine, de Phil-Deux, l'oncle ivrogne, de même que de tous les lieux qu'ils ont fréquentés: SaintJean-de-Dieu, Trois-Pistoles, Morial-Mort. Toujours le même monde qui se fait et se défait selon les secousses psychiques de l'imagination en feu de Victor-Lévy Beaulieu.

Au centre, l'image irradiée de Judith femme d'Abel, maîtresse de Julien avec qui elle s'est enfuie à Miami laissant seul et désemparé le «si pauvre Abel". Elle est toujours amoureuse (malgré le temps et les événements) de Steven qui naguère l'a abandonnée aux mains d'Abel pour aller traduire James Joyce à Paris: Judith, enceinte (de qui? de Julien? de quoi? d'un chat?), erre on ne sait trop où à la recherche d'elle-même et sans doute aussi de Steven le fugitif. 
Don Quichotte de la démanche: un monde en délire, fêlé, par où s'échappe un douloureux cri d'amour. C'est celui d'Abel, irrémédiablement seul, pris au piège, englué dans les mille images qui se sont tissées dans sa tête et qui forment un tragique écran entre Judith et lui:

Je vais essayer de changer, Judith. Si je n'écrivais plus de romans, cela te conviendrait-il?

[...]

Si pauvre Abel. Tu sais bien que tu ne pourras jamais cesser d'écrire! Tu es habité par tes monstres, ce n'est pas toi qui les habites. Et les gardant muets au fond de toi, que t'arriverait-il? Au moins, Nelligan ètait poète, lui! (p. 72-73)

Et devant cette quadrature du cercle, Abel continue d'écrire sur ses caisses d'oranges, continue de boire... et d'aimer, en solitaire éperdu qu'il est, Judith qui a fini «par en finir une fois pour toutes".

Abel se meurt donc à Terrebonne en compagnie de ses deux chats Castor et Pollux, deux jumeaux qui n'en sont pas puisque Castor est la mère et Pollux, le rejeton: très ètrange! Très étrange aussi cette mort atroce de Castor, blessée mystérieusement à la bouche, pissant le sang et le pus et finalement tuée à coups de carabine par Abel. Cela ressemble à une allégorie: celle de la mort de Mam Beauchemin, emportée, elle, du bas-ventre et amèrement pleurée par Jos.

Mais les “étrangetés" ne manquent pas dans les romans de Beaulieu, je ne m'en étonnerai donc pas trop. Pas plus d'ailleurs que de la présence de Goulatromba, le cheval aimé de Malcomm Hudd qui réapparaît soudain dans le décor. Cela n'est-il pas naturel puisque Malcomm avait quitté sa femme et son bungalow de Terrebonne après avoir eu une violente dispute avec elle au sujet de son cheval qu'il voulait à tout prix faire entrer dans la maison! Il faut croire que Goulatromba n'était pas mort et qu'il errait dans les parages de Terrebonne. A moins que Malcomm ne soit tout simplement le double d'Abel. «ll faudra bien qu'un jour la vérité se fasse et qu'on sache que Satan Belhumeur, Malcomm Hudd, Jos le Poilu et Buddha ne sont au fond que le même personnage Homosexuel, Platonique et Neurasthénique" (p. 72), disait Jos (ou serait-ce l'auteur?) dans Jos Connaissant. En fait Victor-Lévy Beaulieu a commis là une malheureuse indiscrétion qu'il faudrait à tout prix effacer. Car son écriture romanesque repose sur ce quiproquo. Comment aurait-il pu écrire la Nuitte de Malcomm Hudd, Oh Miami Miami Miami et Don Quichotte de la démanche, trois romans qui répètent en substance le même drame mais de façon apparemment si différente s'il avait avoué la similitude des personnages?

Puisque dans ce compte rendu je ne veux pas insister sur cet aspect mais m'en tenir plutôt à Don Quichotte je dirai simplement que Goulatromba et même Jim, le frère homosexuel de Judith, avec lequel Abel a failli avoir une aventure (cf. Faux Indien dans $O h$ Miami) ne sont que des personnages secondaires alors que Judith de même que le bébé qu'elle porte dans son ventre occupent tout l'espace romanesque. 
Pourquoi faut-il qu'entre Judith et Abel il n'y ait aucun terrain d'entente? Abel connaît la réponse: c'est parce qu'il ne peut. s'empêcher d'écrire des choses malsaines. Voilà pourquoi il ne cesse de répéter que "les mots ne [sont] là que pour le tromper. Les mots ment[ent]..." (p. 28) Et malgré tout il continue, il s'obstine maniaquement à décapuchonner son stylo-feutre même s'il sait que «quelques dizaines de milliers de mots griffonnés sur du papier rose le menac[ent], risqu[ent] de détruire tout ce qu'il [peut] y avoir de bon en lui, notamment la possibilité de pouvoir un jour tout recommencer avec Judith ". (p. 196)

L'acte d'écrire apparaît donc, pour Abel, comme un acte sacrilège, comme un viol perpétré non seulement contre la personne de Judith mais contre la tribu entière des Beauchemin. Ce n'est pas sans raison que Jos (dans le rêve fascinant que fait Abel) s'attaque violemment à l'entreprise romanesque d'Abel: “Et c'est pourquoi j'ai dû écraser mon frère Abel dont l'entreprise ne pouvait faire de nous tous que des morts, mémorables sans doute, mais seulement des morts. [...] Je dis non aux héros de papier, je refuse que nous soyons seulement des phrases sous la plume de mon frère. " (p. 229)

Mais la campagne (avortée) de dénigrement de Jos contre Abel vaut ce qu'elle vaut: Abel n'en continue pas moins à tuer Judith de ses mots tout comme il a tué sa mère et les siens. Pour lui il n'y a aucune porte de sortie. Abel est inexorablement rivé à son mystérieux cheval et tel un Don Quichotte éperdu et égaré sur les terres québécoises, il pointe, menacé et menaçant, son terrible stylo à pointe de feutre.

Le résultat est tout de même assez étonnant. Don Quichotte de la démanche rachète magistralement la Nuitte de Malcomm Hudd et Oh Miami Miami Miami, deux romans qui n'étaient, somme toute, que des préludes à celui, magnifique, qui vient de naître.

André Vanasse

1. Montréal, Éditions de l'Aurore, 1974. 